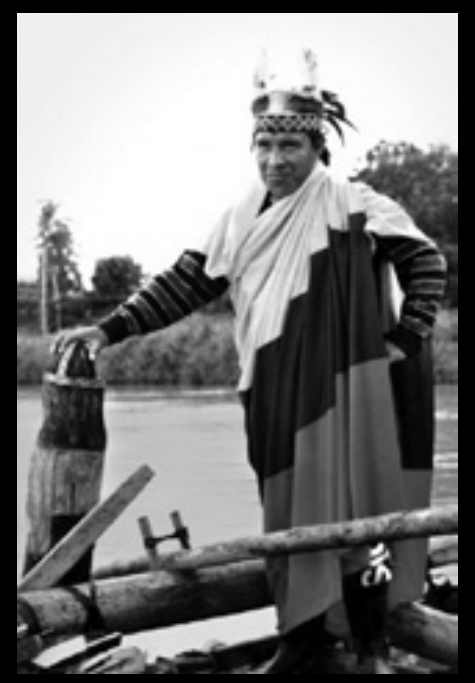

Kimy Pernía Domicó, líder embera que denunció por primera vez en el exterior e impacto de la represa Urrá en su pueblo. En el 2000 fue secuestrado y asesinado por grupos paramilitares. Archivo personal de Marta Pernía, 1994. 


\section{Conflictos ambientales y movimientos sociales: el caso del movimiento embera katío en respuesta a la construcción de la represa Urrá (1994-2008) Environmental conflicts and social movements: the case of the Embera-Katío Movement in response to the construction of the Urra Dam (1994-2008) \\ Conflitos ambientais e movimentos sociais: o caso do Movimento Embera Katío em resposta à construção da Usina Urrá (1994-2008)}

\author{
Yeimmy Rocío Leguizamón Castillo \\ Investigadora independiente \\ bastet83@gmail.com
}

Este artículo se desprende de la monografía de grado presentada para optar por el título de Licenciatura en Ciencias Sociales en la Universidad Distrital Francisco José de Caldas, titulada «Historia del Movimiento Ambiental Embera Katío 1994-2008», la cual fue realizada bajo la dirección de José Novoa en 2010.

\section{Resumen}

Este artículo analiza cómo los conflictos ambientales dan cuenta de la disputa de intereses entre actores sociales por la apropiación de la naturaleza, que desde el ambientalismo se encuentran orientando la acción social a la invención de un nuevo modo de producción y desarrollo respetuoso de las diferencias culturales de los pueblos, y promotor de la conservación y participación activa de las comunidades en la gestión sustentable de los recursos, que les asegure a todos un acceso equitativo a sus beneficios y una mejor calidad de vida. Específicamente en este documento se estudia la historia del proceso de movilización de la comunidad embera katío del Alto Sinú en resistencia a la construcción en su territorio del proyecto hidroeléctrico Urrá I y Urrá II, identificando sus motivaciones, los intereses que convergen sobre sus tierras y los actores que aportaron al desarrollo de la movilización.

\section{Palabras clave}

conflictos ambientales; ambientalismo; movimiento indígena

\section{Abstract}

This article analyzes how environmental conflicts shed light on the dispute of interests between social actors for the appropriation of nature. Since environmentalism, they guide social action to the invention of a new mode of production and development that respect the cultural differences of the inhabitants, as well as promote conservation and active participation of the communities in the sustainable management of resources to ensure everyone equal access to its benefits and a better quality of life. This document studies specifically the history of the mobilization process of the Embera-Katío community from the Alto Sinu, in resistance to the construction of the hydroelectric project Urra I and Urra II in their territory by identifying their motivations, the interests that converge on their land and the actors who contributed to the development of the mobilization.

\section{Keywords}

environmental conflicts; environmentalism; indigenous movement

\section{Resumo}

Este artigo analisa a forma como os conflitos ambientais estão a perceber a disputa de interesses entre atores sociais pela apropriação da natureza, uma vez que o ambientalismo guia a ação social para a invenção de um novo modo de produção e desenvolvimento respeitoso das diferenças culturais dos povos, e promotor da conservação e participação ativa das comunidades na gestão sustentável dos recursos, que assegurar para todos acesso equitativo a benefícios e melhor qualidade de vida. Especificamente este documento estuda a história do processo de mobilização da comunidade embera katío do Alto Sinú em resistência à construção no seu território do projeto hidroelétrico Urrá I e Urrá II, identificando as motivações, os interesses que convergem sobre suas terras e os atores que apoiaram para o desenvolvimento da mobilização.

\section{Palavras-chave}

conflitos ambientais; ambientalismo; movimento indígena 


\section{Introducción}

El desmedido deterioro de la naturaleza ha generado consigo el desmejoramiento de la calidad de vida de las comunidades, lo que ha motivado movilizaciones locales en defensa de su espacio, apoyadas en redes solidarias de cooperación con diferentes sectores sociales (comunidades, intelectuales, profesionales, activistas, estudiantes, organizaciones, etc.). De esta manera, se movilizan conjuntamente antiguos y nuevos actores políticos que buscan generar vías de desarrollo alternativo basadas en el reconocimiento de la diversidad cultural, el desarrollo sustentable y la democracia participativa.

A diferencia de algunas movilizaciones ecologistas de los países del primer mundo que sientan sus bases en prácticas de conservación y control de contaminación, los problemas sociales que se derivan de la sobreexplotación de los recursos o de la afectación de un entorno natural en contextos como el colombiano motivan en las comunidades procesos de movilización que parecen estar más cercanos al ambientalismo que al ecologismo. Esto es así en tanto el primer concepto logra trascender al ecologismo de los países desarrollados al incorporar la dimensión social como interrelacional a las condiciones naturales del entorno, $y$, en este sentido, logra mostrar el vínculo entre la satisfacción de las necesidades y demandas de las comunidades con el entorno natural en el que se desarrollan. Así, las movilizaciones sociales que se generan en respuesta a los impactos ambientales sobre un territorio revelan, antes que ideas de conservación per se, verdaderas luchas por la supervivencia, según lo señalan corrientes como el ecologismo popular.

Si bien en Colombia continuamente se registran este tipo de movilizaciones en las que comunidades expresan su rechazo a la lógica depredadora del desarrollo, a la vez que han forjado alianzas dentro y fuera del país, han incidido en el ámbito legal y han marcado hito dentro del ambientalismo colombiano; hasta ahora son escasas las investigaciones que han abordado la historia de estas movilizaciones con miras a reconstruir, al mismo tiempo, la historia del movimiento ambiental colombiano.

En el marco de este escenario se encuentra el conflicto ambiental desatado por la construcción de la represa de Urrá en el territorio del pueblo embera katío del Alto Sinú.

La llegada del proyecto hidroeléctrico implicó para varias poblaciones asentadas sobre la cuenca del río Sinú e inmediaciones del Parque Nacional Natural Paramillo (PNN) la transformación violenta de su entorno y de las relaciones que habían tejido tradicionalmente con él.

Probablemente una de las comunidades que se vio más afectada al recibir de manera mucho más directa el impacto físico de la construcción de la represa fue el pueblo embera katío del Alto Sinú (inmediaciones del municipio de Tierralta, Córdoba), lo cual afectó profundamente sus estructuras socioculturales y generó una fuerte resistencia a la visión de desarrollo que se pretendía imponer en oposición a las prácticas que tradicionalmente habían definido.

Para el estudio de este caso se articularon tres ejes temáticos de análisis: las construcciones socioambientales coexistentes en el espacio del Alto Sinú para identificar las tensiones históricas entre sus pobladores; el análisis sociológico de las estructuras de movilización para abordar la caracterización y organización del movimiento; y finalmente la valoración de las acciones de protesta del movimiento en el marco de un carácter en el que convergen las reclamaciones propias del movimiento indígena y el ambientalismo, característica que lo ha posicionado como una de las luchas más icónicas en la historia reciente del movimiento ambiental del país, debido al alcance de sus reclamaciones aun fuera del país.

Esto último se explica a partir de la inserción de la lucha en el marco del despertar de la conciencia ecológica a nivel planetario y la admiración mundial de las concepciones tradicionales indígenas como auténticas relaciones sustentables y equitativas con la naturaleza, según los planteamientos de La construcción del nativo ecológico de Astrid Ulloa ${ }^{1}$.

Este trabajo toma como perspectiva de análisis la idea de la interrelación hombre-naturaleza en las construcciones culturales y las significaciones atribuidas a un entorno natural, de manera que

\footnotetext{
1 Astrid Ulloa, La construcción del nativo ecológico: complejidades, paradojas y dilemas de la relación entre los movimientos indígenas y el ambientalismo en Colombia (Bogotá: Instituto Colombiano de Antropología e Historia, Colciencias, 2004).
} 
cuando se da una perturbación sobre el entorno natural inmediatamente se afectan las estructuras sociales, culturales y económicas de una población.

\section{Contexto histórico-espacial del movimiento}

Los grupos humanos establecen interacciones con el contexto natural que habitan, de esta manera crean en un momento del tiempo y del espacio territorialidades y territorios imbuidos de sus propias construcciones culturales, también conocidos como espacios socioambientales, escenarios que a su vez determinan y construyen al ser humano ${ }^{2}$. Este enfoque reconoce que existe un fuerte vínculo entre ecosistema y cultura, en la cual también los sujetos establecen relaciones de poder y dominación por el predominio de su territorialidad.

En este sentido, los actores, las problemáticas y los intereses que se enfrentan en el caso del pueblo embera katío del Alto Sinú y el proyecto Urrá conviene abordarlos en el marco del proceso histórico de apropiación y transformación de la cuenca del Sinú, que permita la lectura de las relaciones socioambientales latentes y en disputa.

El conflicto debe reconocerse dentro del contexto de permanente lucha por el acceso a la tierra que se registra en Córdoba, en el que la comunidad indígena ha visto vulnerado su territorio a través de diferentes formas de apropiación puestas en marcha por el hombre mestizo: en primer lugar, las actividades económicas que se han desarrollado en el departamento como la explotación maderera, la agricultura intensiva y la ganadería han deteriorado la naturaleza, y han despojado de sus tierras a los campesinos y a las comunidades indígenas. Los atractivos recursos que ofrece el Alto Sinú, además de la necesidad de búsqueda de nuevas tierras, han atraído varias oleadas de colonización, que han logrado adentrarse en territorio indígena, sin que hasta ahora las instituciones gubernamentales correspondientes hayan gestionado el saneamiento del resguardo para proteger a la población indígena. En tercer lugar, la presencia de grupos armados en disputa por la hegemonía de espacios estratégicos ha afectado

2 Felipe Cárdenas Támara, Antropología y ambiente; enfoques para una comprensión de la ecosistema-cultura (Bogotá: Pontificia Universidad Javeriana, 2002), 13, 17 y 35. a la población civil incrementando el desplazamiento forzado y aumentando los asentamientos en la periferia de municipios como Tierralta y Montería. Esta situación no ha sido ajena a la comunidad indígena, que ha recibido permanentes amenazas que han resquebrajado la seguridad y la unidad de sus familias. En cuarto lugar, el diseño de proyectos como Urrá en la región se apuntala como una forma de dominio del territorio y aprovechamiento de los recursos naturales para su comercialización, que se inscribe en el lenguaje del progreso y el beneficio común, pero que, en realidad, sigue favoreciendo la extensión de las propiedades de terratenientes y el poder de las élites de la costa Atlántica.

Ahora bien, la conjunción de todos los intereses que se ciernen realmente sobre el control territorial de la cuenca del río Sinú y el PNN Paramillo, y que están ocultos detrás del proyecto multipropósito Urrá, parecen demasiado explícitos, en tanto es de amplio conocimiento que el sector ganadero y hacendado desde tiempo atrás, para extender las áreas de pastoreo y cultivo, se ha valido de terraplenes, muros de contención, o presas de riego para la eliminación de cuerpos de agua como pantanos, pozos, ciénagas y caños, a la par que se ha talado de manera insostenible la selva con el mismo fin, rivalizando por el control de la tierra con otras actividades económicas como la pesca. Tal como lo plantea la Corte Constitucional:

Sea para ampliar los pastizales o para cultivos, los cuerpos de agua que componen el sistema de humedales del Sinú vienen siendo persistentemente rellenados y desecados por los particulares, que se niegan a aceptar las características geográficas propias de esta cuenca aluvial, como las más convenientes para la conservación de los ecosistemas en los que viven, o que simplemente no están interesados en la conservación de los mismos ${ }^{3}$.

Luego, estos terrenos son definidos como baldíos y titulados a latifundistas. Esta práctica ha sido común a lo largo del Sinú, y por esta razón Kimy Pernía, reconocido líder del pueblo embera, no dudaba en afirmar que el objetivo real de Urrá era propiciar el clientelismo a través de la empresa y aumentar el número de propiedades terratenientes a costa de la desecación de los cuerpos de

3 Corte Constitucional, Sentencia T-194 de 1999. 
agua $^{4}$. Esta tendencia favorecida por el Instituto Colombiano para la Reforma Agraria (Incora) fue criticada por la Corte Constitucional, quien, por medio de la citada Sentencia T-194 de 1999, la prohibió y ordenó la recuperación de estos terrenos para el dominio público:

[...] Este Instituto no solo ha dejado de cumplir en Córdoba la función que legalmente le corresponde, sino que viene actuando con desviación de sus objetivos, en perjuicio de aquellos sectores de la sociedad cuya calidad de vida debe promover, mientras permitió que se agravara la concentración de la propiedad rural en todo ese departamento [...] [En tal sentido se ordena] al Instituto Colombiano para la Reforma Agraria Incora-, que suspenda inmediatamente la política irregular de adjudicar como baldíos los terrenos públicos ubicados en las márgenes de las ciénagas de Córdoba, y las áreas que resulten del relleno de los humedales, lagunas, pozos, lagos o caños de la hoya del Sinú 5 .

El cumplimiento de esta disposición no ha registrado mayores avances, demostrando el evidente interés de algunos sectores de mantener controlado el crecimiento natural del río Sinú; incluso los planes que se han proyectado desde el Estado demuestran ser partidarios de esta estrategia, concentrando para ello recursos y esfuerzos desde los años sesenta.

Justamente esto pasaría con los entes encargados de la vigilancia y protección de los recursos naturales: la Corporación Autónoma Regional de los Valles del Magdalena y del Sinú (cvM) -hoy denominada Corporación Autónoma Regional de los Valles del Sinú y San Jorge (cvs)-, y el Instituto Nacional de los Recursos Naturales Renovables y del Ambiente (Inderena) ${ }^{6}$. La figura antecesora al Inderena en la región sería la cvm. En virtud de esta función, el Gobierno nacional le encomendaría la misión de elaborar un estudio de obras encaminadas «a la regularización y control del río Sinú y al beneficio de las

4 Kimy Pernía, «El proyecto Urrá según lo hemos visto los embera». En Memorias Foro ¿Para dónde va Urrá? Incidencias y perspectivas de la ejecución del proyecto hidroeléctrico de Urrá, ed. Gloria Amparo Rodríguez (Bogotá: Instituto de Estudios Ambientales IDEA, Universidad Nacional de Colombia, 2000).

5 Corte Constitucional, Sentencia T-194 de 1999.

6 Instituto que estaba a cargo del manejo de los recursos naturales y el medio ambiente a nivel nacional, y que fue liquidado por disposición de la Ley 99 de 1993. En este momento dichas funciones, según la misma ley, son asumidas por las corporaciones creadas en todo el país. tierras situadas en el valle del mismo río» ${ }^{7}$ con la intención de solicitar un empréstito al Banco Interamericano de Desarrollo, por medio del documento base denominado Plan Maestro de Desarrollo de la Hoya Hidrográfica del Río Sinú.

$\mathrm{El}$ informe presentado por la CVM detallaría las características físicas de los recursos de la cuenca y las actividades económicas potenciales que ofrecerían estos, lo que parecía ratificar la importancia de lo que estudios precedentes habían considerado «el globo de tierra más importante en proceso de desarrollo en el hemisferio occidental $\aleph^{8}$. Entre las observaciones hechas para resolver el tema de las inundaciones y el aprovechamiento de las tierras, se retoma la idea de la investigación de R. J. Titon \& Associates Inc. de construir una represa para regular los recursos acuíferos relacionados con el Sinú en el punto denominado angostura de Urrá:

Este control tendría como base la construcción de la presa de Urrá [...]. Una vez controlado el río, unas 310.000 hectáreas de tierras muy fértiles podrían ser irrigadas mediante la construcción de simples obras, y la instalación en la presa, de grupos turbo-generadores, haría posible la generación de energía eléctrica con una potencia firme de 120.000 kilovatios 9

Dichas estimaciones apoyadas en las investigaciones que harían en 1968 las firmas Integral y тAмBs, aseguraban que la represa debía estar acompañada de la puesta en marcha de distritos de riego para lograr a cabalidad el control de la zona, además exaltaban la ventaja de poder utilizar a Urrá como embalse de regulación y central hidroeléctrica.

La intención de intervenir la cuenca del Sinú se mantuvo a lo largo de las siguientes décadas; por esta razón, hacia los años noventa, el Estado colombiano replantearía el Plan Maestro de Desarrollo de la Hoya Hidrográfica del Río Sinú, ahora con el nombre de Plan Maestro de Desarrollo Integral de la Cuenca Hidrográfica del Río

7 Corporación Autónoma Regional de los Valles del Magdalena y del Sinú, Bases para un estudio del Desarrollo Integral de la Hoya Hidrográfica del Río Sinú, Programa de Investigación presentado a la consideración del Banco Interamericano de Desarrollo (Bogotá, 1961).

8 Edmundo López Gómez y Germán Bula Hoyos, Urrá: La más importante obra para el desarrollo de la Costa Atlántica (Bogotá: A.B. Comunicaciones, 1985), 15.

9 Corporación Autónoma Regional de los Valles del Magdalena y del Sinú, Bases para un estudio, 3. 
Sinú (PMDICHs), perfilándolo como un proyecto promotor del desarrollo económico y social en la zona, a través de la puesta en práctica de la agroindustrialización y la conexión con el mercado internacional. Entre las acciones a realizar el PMDICHS menciona:

La creación de un puerto de aguas profundas en inmediaciones de la bahía de Cispatá, la construcción de 15 grandes distritos de riego a lo largo de la cuenca y de la carretera «Marginal de la Costa» que unirá la zona con Urabá, el fomento de la industria camaronera, la implantación de extensas áreas de monocultivos forestales a manera de sumideros de carbono en la Cuchilla de Cispatá, la construcción y operación de la hidroeléctrica Urrá I y II, así como el perfeccionamiento de la infraestructura turística en la región ${ }^{10}$.

Comunidades como los embera katío y la Asociación de Productores para el Desarrollo Comunitario de la Ciénaga Grande del Bajo Sinú (ASPROcig) han criticado la orientación del PMDICHs como una propuesta de desarrollo no sustentable opuesta a las economías agrarias tradicionales que degrada la naturaleza y, al mismo tiempo, continúa favoreciendo a grandes propietarios de tierras. En este orden de ideas, las hidroeléctricas de Urrá entrarían a formar parte de una cadena de megaproyectos que concentran sus intereses a lo largo de la cuenca del Sinú.

\section{Impacto ambiental}

Por medio de las represas, el hombre modifica y destruye la naturaleza de manera irreversible, generando así graves afectaciones sobre el entorno social y natural. Tal como lo han advertido las investigaciones al respecto, los impactos que causan en el entorno pueden difundirse a lo largo de toda la cuenca y en una franja extendida de tierra a lado y lado del río. Este fenómeno ha sido percibido con la construcción de Urrá al inundar 7.400 hectáreas de selva ${ }^{11}$ y extender otros males a lo largo del curso del río Sinú.

10 Cabildos Mayores Embera Katío de Río Sinú y Río Verde, «El Plan Maestro de Desarrollo Integral de la Cuenca Hidrográfica del Río Sinú». http://www.camaemka.org/descargas/Grupo_semillas.pdf (consultado el 5 de mayo de 2009).

11 Según lo que señala Paul Sánchez, la inundación afectó ese número de hectáreas, pero la destrucción de la selva alcanzó de 8500 a 9000 hectáreas, si contemplamos el impacto de la construcción de
Entre las secuelas propias que se derivan de la alteración del curso natural del río, se encuentra el hundimiento progresivo (subsidencia) de los sedimentos que anteriormente circulaban y alimentaban el delta. Esta situación es la que determina la sedimentación de las aguas de la represa, proceso que, para el caso de Urrá, se ve acelerado por las constantes precipitaciones en la zona, sumado a la deforestación que se aprecia en el Alto Sinú, características que según los cálculos reducen la vida útil del proyecto a menos de 20 años. Del mismo modo, la corriente sin sedimentos del río ha erosionado de manera progresiva los lechos y reclamado con mayor fuerza a través de las inundaciones las riberas, en sectores distantes de la represa como Montería, Cereté y el Bajo Sinú, tal como lo señaló hace unos años la Defensoría del Pueblo ${ }^{12}$.

Los estudios de Dames y Moore sobre Urrá advertían especialmente sobre el deterioro del agua del río debido a la descomposición de la vegetación inundada, que disminuye la concentración de oxígeno y favorece la emisión de dióxido de carbono y gas metano, conocidos gases de efecto invernadero (GEI). Las características de la represa de Urrá agudizan este problema:

Las aguas de la represa Urrá I, que es más angosta, profunda y pequeña en superficie, tiene menos posibilidades de mezclarse, aún con la ayuda del viento. A pesar de décadas de experiencias con tales reservorios defectuosos, los planificadores de Urrá nunca se preocuparon de este problema tropical, y simplemente copiaron los diseños que vienen de climas templados, donde los cambios estacionales de temperatura, imponen un intercambio obligatorio de las capas termales en sus cuerpos de agua ${ }^{13}$.

Además, las descargas del fondo del embalse, a través de las turbinas, depositan aguas estancadas al caudal río abajo, contaminando la corriente y afectando la vida acuática. La afectación del equilibrio hidrológico por la incidencia de la represa de Urrá ha afectado la red trófica vinculada, y especies

carreteras y campamentos de estudio de factibilidad. Paul Sánchez Puche, entrevistado por el autor, Bogotá, 5 de marzo de 2009.

12 «Debate contra Urrá», El Tiempo [Bogotá], 2 de octubre, 2002.

13 Kashyapa Yapa, «El asesinato ceremonial del Río Sinú- Parte II». http://kyapa.tripod.com/urra/asesinatoceremonial2.htm (consultado el 30 de agosto de 2009). 
animales se han visto amenazadas por las condiciones de un río ahora estable e intervenido.

Probablemente el caso emblemático de este impacto sobre la fauna ha sido el relacionado a la desaparición del bocachico a lo largo de la cuenca. E1 informe de Dames \& Moore lo advertía, y años después, aun antes de la entrada en operación de Urrá I, seguirían varias voces de alerta, incluso desde la Corte Constitucional:

[...] Esta Sala advertirá al Ministerio del Medio Ambiente que deberá prestar especial atención a este impacto previsible, y solo conceder la licencia para el llenado de la presa y funcionamiento de la hidroeléctrica, cuando se garantice la adopción de las medidas necesarias para que el aprovechamiento del agua en la producción de energía, no signifique la extinción del recurso ictiológico que aparece como gravemente amenazado ${ }^{14}$.

Sucede, que el bocachico es un pez migratorio que antes de la construcción de la hidroeléctrica ascendía por el río Sinú hasta el río Verde para desovar en sus aguas llenas de oxígeno. Este punto con la construcción de Urrá coincidía con el tramo que recibe las aguas servidas de la casa de máquinas, cargadas de hierro disuelto y ácido sulfhídrico, altamente letales para los peces y los huevos, lo que significa que cuando se bloquea este ciclo reproductivo se amenaza la existencia del bocachico en el río. El pez tampoco se encuentra en capacidad de atravesar los túneles por los que bajaba con enorme presión el caudal de agua, y por esta razón miles de ellos quedaron atrapados y murieron ${ }^{15}$. La mortalidad de diferentes especies de peces continuaría hasta niveles críticos en los años siguientes. $\mathrm{Al}$ respecto es ilustrativo un comunicado de los Cabildos $\mathrm{Ma}$ yores de Río Sinú y Verde:

De nuevo estamos informando que la mortalidad de
peces no cesa, el día miércoles 16 de abril mientras
miembros de la comunidad indígena pescaban con
anzuelo en las bocas de Río Verde, el río empezó a
crecer y el lodo que bajaba enturbió las aguas del em-
balse la cual ocasionó una gran mortalidad de peces,
era triste observar como la Picuda o rubio (rullo), la
charua (amparra), el bagre sapo (ojo), el barbudo (ya-
rri), la doncella, el moncholo (nusi), el liso (babu) y el

14 Corte Constitucional, Sentencia T-194 de 1999.

15 «Miles de peces atrapados en Urrá», El Tiempo [Bogotá], 1 de febrero, 1996. bocachico, los cuales alcanzaban tallas hasta de $50 \mathrm{~cm}$, eran aprovechados por los goleros (gallinazos) ${ }^{16}$.

\section{Impacto social}

Los efectos negativos que se derivan de la construcción de una represa deterioran el espacio natural, y por consiguiente alteran la vida de las comunidades que viven en sus inmediaciones, en tanto la satisfacción de las necesidades, las actividades económicas y las construcciones culturales se ven abruptamente transformadas de manera definitiva. Esta serie de consecuencias, tal como sucede con los impactos ambientales, se extiende a diferentes poblaciones concentradas río arriba y río abajo, acrecentando la cifra de personas afectadas $\mathrm{y}$ las zonas perjudicadas que inicialmente no se consideraban dentro del radio de acción. Con esto se demuestra la interconexión de la naturaleza y la complejidad de los problemas que se desatan.

Las primeras investigaciones que analizaban la magnitud del impacto que generaría Urrá ya observaban con preocupación de qué manera se afectaría la relación entre el río y las comunidades, e incluso señalaban como los lugares más vulnerables el Alto Sinú arriba de la Angostura de Urrá, las Ciénagas Grande de Lorica y Betancí, y el delta del río Sinú, incluyendo la zona estuariana ${ }^{17}$.

La cadena de impactos sociales inicia con el desplazamiento de las comunidades asentadas en el área de inundación. Se considera que afectó a 16.000 habitantes de la zona, entre los que se encuentran 5462 campesinos, 10.425 colonos y 113 indígenas embera katío ${ }^{18}$. El proceso elevó la incertidumbre de esta población y la cantidad de oportunistas que terminan reclamando tierras. Los nuevos territorios por lo general no ofrecen a estas personas las mismas condiciones y medios de subsistencia de las zonas expropiadas, entorpeciendo su desarrollo y autonomía al quedar sujetos a la compensación monetaria dada por la

\footnotetext{
16 Cabildos Mayores Embera Katío de Río Sinú y Río Verde. «Mortalidad de peces en el Alto Sinú; los cabildos mayores de los ríos Sinú y Verde reiteran su preocupación ante la opinión pública» (24 de abril, 2003). http://www.gratisweb.com/embera_katio/pez.htm. (consultado el 10 de agosto de 2009).

17 Alberto Alzate Patiño et al. Impactos Sociales del proyecto Hidroeléctrico de Urrá (Montería: Fundación del Caribe, 1987), 145.

18 «Otra vez paralizada Urrá», El Tiempo [Bogotá], 19 de octubre, 1992.
} 
empresa ejecutora del proyecto o nuevamente al desplazamiento para la búsqueda de mejores condiciones. Las comunidades campesinas del Alto Sinú que fueron reubicadas, por ejemplo, tuvieron que enfrentarse al drama de abandonar sus terruños para ser llevados a lugares sin servicios públicos básicos y expuestos a enfermedades y riesgos.

Diferentes actividades económicas también se vieron perjudicadas a lo largo del río, empezando por la inundación de los terrenos más fértiles del resguardo del pueblo embera katío, así como las márgenes del río sobre las que acostumbraban a sembrar arroz ${ }^{19}$. Además, el bocachico como parte de su base alimentaria y su cosmogonía desapareció con la represa, afectando gravemente a la comunidad indígena y a otras poblaciones asentadas río abajo como los pescadores de Lorica, Chimá, Momil, Purísima, San Sebastián y San Bernardo del Viento, que han visto cómo se acaba la pesquería artesanal de la zona.

La salud de las poblaciones afectadas también se ha visto alterada por la proliferación de enfermedades asociadas con las aguas en mal estado. Los caños y ciénagas en proceso de extinción, al igual que las orillas de la represa con la biomasa en descomposición, ofrecen en sus aguas estancadas hábitats propicios para el desarrollo de mosquitos y otros organismos transmisores de enfermedades como la malaria y el dengue hemorrágico. Existen también serios riesgos nutricionales para estas comunidades, en tanto muchas de ellas han perdido la subsistencia alimentaria por la extinción de la mayoría de las especies ictiológicas.

Para el caso de la comunidad embera katío, con la construcción de la represa de Urrá, el impacto social y cultural fue mucho más grave con la desaparición de territorios ancestrales y sagrados, y la eliminación para siempre de la navegación tradicional debido a la reducción de la velocidad de la corriente en el embalse, lo cual ha dificultado el transporte y la comunicación de la comunidad con otras poblaciones. Así mismo, se generó la división interna del pueblo indígena, aumentando consigo el desarraigo a través de la práctica

19 Consejo Nacional Indígena de Paz (ConIP), «Situación de Derechos Humanos y Derecho Internacional Humanitario Pueblo Embera Katío» (2006). http://www.pcslatin.org/eventos/2006/mision_internacional/cordoba.pdf (consultado el 30 de octubre de 2008). de valores ajenos a su cultura. Con la indemnización ofrecida por la Empresa Urrá se ha impulsado un modelo económico dependiente, inscrito en las lógicas de mercado y totalmente opuesto a los proyectos productivos tradicionales de la comunidad. Al respecto, es ilustrativo el comentario que hace Paul Sánchez:

Cuando Urrá les paga lo que hacen es que esa cultura se transgreda, entonces empiezan a comprar celulares, a comprar ron, a prostituirse los hombres y las mujeres, todo esto ya se había denunciado antes de que se construyera a Urrá I por el movimiento ambiental, en este momento la comunidad prácticamente ha perdido gran parte de su originalidad [...]. Un número muy alto [de emberas] está en Cartagena, Montería, Medellín, Bogotá, La Guajira [...]. Ya la comunidad no esta como estaba antes. ¿Qué están haciendo en estas ciudades? Venden baratijas, trabajan en las casas de familia de los ricos (de sirvientas las mujeres), otros están trabajando en mototaxis, otros estaban trabajando en la construcción, otras están trabajando en la prostitución, el daño más grande que ha sufrido la cultura embera es ese ${ }^{20}$.

La muerte y la inseguridad también han llegado al resguardo derivadas de la construcción de la hidroeléctrica. Las vidas que ha segado han estado relacionadas con asesinatos por parte de actores armados ilegales y accidentes por la alteración del entorno, tal como lo muestran los comunicados de los Cabildos Mayores:

El día 2 de marzo de 2005 a las 9:30 de la mañana en el sitio conocido como Torres cerca de la desembocadura del río Verde al embalse de Urrá, nuestro hermano Juan Lucas Chara Domicó murió en un trágico accidente provocado por la cantidad de lodo que se acumula en este sitio del embalse. Nuestro hermano Juan Lucas manejaba una canoa con motor fuera borda, y en este sitio en épocas de verano, la profundidad es poca y se acumula gran cantidad de lodo, aquí Juan Lucas para evitar que la canoa se volteara se bajo de esta y el lodo lo empezó a tragar poco a poco, el acompañante que viajaba con él, Luís Enrique Domicó, no pudo hacer nada ya que el lodo movedizo de este sitio se lo impedía. Este hecho se suma a lo ocurrido el 6 de abril del año anterior a las 2 de la tarde, con nuestro hermano Wilson Domicó Bailarín, el cual también murió cuando un árbol podrido, de los que la empresa no quiso quitar al llenar el embalse, cayo sobre su humanidad en el

20 Sánchez Puche, entrevistado por el autor, Bogotá, 5 de marzo de 2009. 
momento en que transitaba en su balsa por el sitio el Caimán en el río Sinú ${ }^{21}$.

Finalmente, se puede concluir que los conflictos derivados de las represas revelan a partir de elementos como los impactos que no son solamente enfrentamientos por el río o por el manejo del recurso hídrico; son conflictos comprometidos con el desarrollo humano y la existencia misma de las comunidades.

\section{Elementos para la caracterización del movimiento embera katío}

Los llamados nuevos movimientos sociales son orientados por acciones políticas disruptivas del sistema social, en tanto buscan tener acceso a la participación e impactar en las políticas del Estado a través de discursos críticos del mundo moderno que exigen que se contemplen modelos socioeconómicos alternativos y realmente incluyentes. De otro lado, el movimiento indígena y el ambientalista han logrado hacer coincidir sus luchas a través del discurso de la identidad y las alianzas intersectoriales, superando así el sesgo de las ideologías y la confrontación de clases sociales que habían abanderado movimientos sociales clásicos, como el obrero.

El caso de los embera katío, si bien corresponde a un movimiento indígena, requiere para su caracterización dar crédito a los alcances y el impacto que han logrado las movilizaciones indígenas. Estas han extendido su discurso más allá de la simple cuestión agraria local que caracterizaba a la protesta indígena de la primera mitad del siglo xx, para entablar diálogo con tendencias ambientalistas que defienden y proyectan sus voces más allá de las fronteras nacionales.

En este sentido, se deben retomar los postulados del ambientalismo para hallar el punto de encuentro que mantiene con el movimiento indígena e interpretar las estructuras de movilización sobre las que se basa específicamente el movimiento embera katío.

21 Cabildos Mayores Embera Katío de Río Sinú y Río Verde, «Muere indígena embera katío en accidente por lodo acumulado por Urrá I» (4 de marzo, 2005). http://www.colombia.indymedia.org/ news/2005/03/22879.php (consultado el 5 de junio de 2009).
El ambientalismo puede ser interpretado como respuesta a una crisis global, que exige reestructurar el orden ético, político y económico de la relación hombre-naturaleza, lo que, en consecuencia, lo convierte en un movimiento que busca abrir espacios de desarrollo alternativo respetuoso de la diversidad cultural, aliado del desarrollo sustentable y la autogestión de los recursos. En este sentido, concentra su lucha en el acceso a la participación en la gestión, al igual que propone modelos sociales alternativos al hegemónico.

En el movimiento embera katío sucede algo particular, y es que si bien el discurso del ambientalismo estaba ya presente dentro de la búsqueda del reconocimiento de la gestión del territorio y los recursos que venían adelantando con antelación el pueblo indígena, no hay conciencia directa de ello, ni es definido en estos términos por los embera. Es solo hasta que el movimiento se haga público y empiece a llegar a otros sectores que sus demandas serán inscritas dentro de la lógica ambiental global.

Este reconocimiento a nivel mundial de la estrecha relación que guardan los pueblos indígenas con sus entornos naturales, así como de la existencia de modelos alternativos de aprovechamiento de los recursos naturales, le ha facilitado al movimiento que estas demandas sean más fácilmente gestionadas, e incluidas en agendas de gobierno y en los círculos de discusión académica internacionales $^{22}$, debido al trampolín internacional que constituye apelar al discurso frontera entre lo indígena y lo ambiental para definir el conflicto.

La lucha agraria, que por mucho tiempo caracterizaría al movimiento indígena y que los representaría como sujetos aislados y premodernos, cambiaría de sentido con el movimiento indígena contemporáneo, en el que los líderes indígenas se han empoderado en el tema de la participación y han sacado provecho al discurso ambiental en auge al conjugarlo con las nociones tradicionales indígenas de la naturaleza. En este sentido, movimientos como el embera katío han establecido con mayor fluidez alianzas con organizaciones

22 Guillermo Wilde, De la depredación a la conservación. Génesis y evolución del discurso hegemónico sobre la selva misionera y sus habitantes» (2007). http://www.scielo.br/scielo.php?pid=S1414$753 \times 2007000100006 \&$ script=sci_arttext\&tIng=en. (consultado el 20 de agosto de 2008). 
ambientalistas y de derechos humanos en el ámbito mundial, posicionándose por sí mismos como interlocutores válidos universalmente, con capacidad de impactar en la opinión pública y proponer políticamente el desarrollo de modelos socioeconómicos alternativos y sustentables.

\section{Las redes del movimiento: cooperación y solidaridad de diversos sectores}

Las redes del movimiento son consideradas por autores como Alberto Melucci ${ }^{23}$ como una red de grupos dentro del movimiento que comparten una identidad colectiva y una dimensión afectiva común que los convoca a la participación. En este orden de ideas, es imposible imaginar que la acción colectiva sea dirigida por un único grupo. Son estas coaliciones de apoyo las que terminan dándole fuerza, movilidad y contundencia al repertorio de confrontación.

Dentro del contexto de lo señalado, debe hacerse referencia al ambientalismo colombiano en tanto históricamente ha sustentado sus acciones en el trabajo conjunto de redes solidarias que desde diferentes sectores y perspectivas del pensamiento ambiental ${ }^{24}$ se han articulado a la lucha y a las discusiones sobre la gestión ambiental de las riquezas naturales del país. En este sentido, el ambientalismo colombiano carece de una estructura organizativa única que oriente las acciones desde una sola tendencia y bajo unos mismos propósitos para todos los actores involucrados:

Se puede afirmar que no existe un movimiento social ambiental con un objetivo y planes en común, con una directiva y una representación nacional, pero sí existe un movimiento ambiental diverso y pluricultural, como la misma naturaleza, donde se expresan múltiples visiones, prácticas, experiencias, conceptualizaciones ${ }^{25}$.

23 Alberto Melucci, Acción colectiva, vida cotidiana y democracia (México D.F.: El Colegio de México, 1999).

24 El ambientalismo colombiano, con los matices personales, grupales y regionales, se mueve entre las corrientes conservacionistas o del culto a lo silvestre, la ecoeficiencia y la justicia ambiental o ecologismo popular. Isaías Tobasura Acuña, «Ambientalismos y Ambientalistas: Una expresión del Ambientalismo en Colombia» (2007). http://www.scielo.br/pdf/asoc/v10n2/a04v10n2.pdf (consultado el 18 de agosto de 2008).

25 Ecofondo, Se hace camino al andar: aportes para una historia del movimiento ambiental en Colombia (Santa Fe de Bogotá: Ecofondo, 1997), 26
No obstante, ha sido esta naturaleza multisectorial de la protesta ambiental la que ha logrado articularse con luchas populares, ha impactado en las políticas públicas y ha dinamizado y expandido las acciones del ambientalismo a planos más allá del local a través de la coordinación de redes de apoyo dentro y fuera del país, tal como se ha presentado a lo largo de las protestas más destacadas de la historia ambiental colombiana.

La lucha del Pueblo embera katío en defensa de su territorio termina convocando alrededor de ella, al ambientalismo colombiano, así como a defensores de derechos humanos y ciudadanos que terminarían cumpliendo una labor fundamental dentro del proceso de movilización embera al posibilitar la difusión de las demandas, presionar para la concreción de acuerdos y garantías y brindar un soporte permanente a las acciones disruptivas. Por lo tanto, la organización del movimiento estaría soportada por diferentes tipos de actores, quienes, según lo proponen McCarthy y Zald, pueden ser constituyentes, adherentes (normales y de conciencia) y beneficiarios potenciales $^{26}$. Los primeros hacen referencia a quienes ofrecen tiempo y recursos al servicio del movimiento en pro de un beneficio común, mientras que los adherentes apoyan o simpatizan con la organización del movimiento, mas no se relacionan con los provechos derivados de la movilización, y finalmente están los beneficiarios potenciales que no pertenecen al movimiento social pero se sirven de manera indirecta de sus logros.

En un primer momento, las reclamaciones del movimiento al acudir a un marco de sentido que no se limitaba únicamente a la reivindicación de los intereses de la comunidad indígena logró extender su discurso a los intereses de campesinos y pescadores, eliminado las barreras culturales y las rivalidades por la posesión del territorio para congregarlos por una misma causa. Estos sectores apoyarían al pueblo embera katío desde organizaciones comunitarias muy significativas como: la Asociación de Productores para el Desarrollo Comunitario de la Ciénaga Grande de Lorica (AsPROCIG), integrada por pescadores, campesinos e

26 Martín Tanaka, «Elementos para un análisis de los movimientos sociales», Revista Análisis político, n. ${ }^{\circ} 25$ (1995): 3-25. 
indígenas; la Asociación de Productores para el Desarrollo Comunitario del Medio Sinú (AProPESCAM), integrada por campesinos, pescadores, mujeres y ambientalistas; y la Asociación Unida de San Antero (aunisan), integrada por mangleros, pescadores, recicladores, mujeres, y ostreros.

En este sentido, podría considerarse que estas organizaciones pertenecen al grupo de los actores constituyentes del movimiento, que cooperan con él al protestar contra una problemática común, pero mantienen sus propias movilizaciones y no se encuentran totalmente adheridas a la organización del movimiento embera. Este es el caso particular de Asprocig, que junto con los Cabildos Mayores coordinan manifestaciones conjuntas, presentándose ante la opinión pública como un bloque opositor a Urrá y al modelo de desarrollo que lo sustenta.

Así mismo, el movimiento embera katío también se encontraría auxiliado de manera coyuntural por las acciones de la comunidad indígena u'wa, como otro movimiento contemporáneo en resistencia a la explotación petrolera en su territorio por parte de la empresa oxy, que bien podría señalarse en calidad de beneficiario potencial del movimiento al encontrarse unida por la fraternidad de ser también un pueblo indígena agobiado por situaciones similares. Por ello, ambas problemáticas serían vinculadas de manera solidaria por el ambientalismo local e internacional, lo que les permitió concentrar la atención y de esta manera movilizar la opinión pública a su favor.

Por otra parte, los actores adherentes del movimiento se encuentran representados en un conjunto de personas y organizaciones nacionales que desde sus propios ejes de acción respaldaron de manera permanente la movilización del pueblo embera katío.

Bajo la asesoría y permanente apoyo de otras organizaciones como la onic, la Comisión Colombiana de Juristas, organizaciones sindicales, organizaciones ambientalistas y organismos internacionales para la protección de los derechos humanos, el pueblo embera katío encontró el respaldo para apelar a acciones legales ante entes internacionales como la Comisión Interamericana de Derechos Humanos, y la Organización Internacional del Trabajo (огт).

Desde el contexto nacional también prestarían un importante apoyo comités y organizaciones ambientalistas como el Comité de Apoyo a las Comunidades del Río Sinú (censat) Agua Viva, Comité Colombia es U`wa, Comité Colombia es Embera, Corporación Ambiental bacata Siglo XXI, Corporación Nuevo Arco Iris, Fundación Ecológica BaCATA y el Comité de organizaciones ambientalistas CANOA, al igual que estudiantes, docentes y ciudadanos del común. Este conjunto de actores impulsarían campañas nacionales de apoyo, así como eventos y seminarios que buscaron informar y captar nuevas redes de solidaridad e impactar en la opinión pública.

En el plano internacional, estas acciones desembocarían en la conformación de la Embera Katío Support Network (EKSN) (Red de apoyo Embera Katío), integrada por una coalición de ong canadienses y estadounidenses relacionadas con el ambientalismo y apoyo indígena en América Latina. Estas promocionaron campañas, acogieron adeptos y generaron estrategias de presión para el respeto de los derechos a través de nuevas tecnologías, como Internet. Precisamente el alcance internacional que logró tomar el movimiento es analizado por Ann C. Mason como una valiosa estrategia de lucha en el marco de lo local y lo global:

La estrategia embera fue movilizar la opinión mundial a favor de su causa para presionar a los gobernantes de las firmas involucradas en el proyecto a tomar parte de la problemática. Su uso de una plataforma global refleja el crecimiento de la influencia de una compleja red de ambientalismo internacional, indígenas y actores antiglobalizantes que forman parte de la cultura política mundial ${ }^{27}$.

\section{Reflexiones finales}

De lo planteado se deduce que la resistencia a la instalación del proyecto multipropósito Urrá en inmediaciones del territorio embera katío se encuentra ligada a una cadena de eventos que han afectado el territorio indígena. En este sentido, la movilización representa no solo inconformidad por la vulneración de sus derechos sobre la tierra, sino también una decidida oposición a esta serie de amenazas que tienden a afectar irreversiblemente

\footnotetext{
27 Ann C. Mason, «Constructing authority alternatives in Colombia: Globalisation transformation of governance». http:www.eldis.org/ assets/Docs/15081.html (consultado el 25 de marzo de 2009).
} 
sobre la unidad, la cultura y la supervivencia embera ligadas a la preservación del territorio.

De otro lado, el conjunto de acciones y las redes de cooperación que desarrollaría el pueblo embera katío lograron proyectar la movilización más allá del contexto local. La lucha indígena, que tendía a ser vista como sectaria y débil (a excepción de los pueblos indígenas del Cauca), alcanza a posicionarse ante la opinión pública con los embera katío como un movimiento que puede fácilmente establecer puentes de comunicación y cooperación con otros sectores sociales, entre ellos el ambientalista, y de esta manera lograr desarrollar importantes acciones que obligan al Estado y a la empresa Urrá a negociar acuerdos. Justamente por este motivo el carácter intersectorial que acompañaría la movilización embera terminaría convirtiéndose en uno de los íconos de la protesta ambiental del país, en la que mejor se demuestra la heterogeneidad del ambientalismo colombiano y los discursos alternativos de apropiación de la naturaleza.

\section{Bibliografía}

\section{Fuentes primarias}

Cabildos Mayores Embera Katío de Río Sinú y Río Verde. «El Plan Maestro de Desarrollo Integral de la Cuenca Hidrográfica del Río Sinú». http://www. camaemka.org/descargas/Grupo_semillas.pdf.

Cabildos Mayores Embera Katío de Río Sinú y Río Verde. «Mortalidad de peces en el Alto Sinú; los cabildos mayores de los ríos Sinú y Verde reiteran su preocupación ante la opinión pública» $(24$ de abril, 2003). http://www.gratisweb.com/embera_katio/pez.htm.

Cabildos Mayores Embera Katío de Río Sinú y Río Verde. «Muere indígena embera katío en accidente por lodo acumulado por Urrá I» (4 de marzo, 2005). http://www.colombia.indymedia.org/ news/2005/03/22879.php.

Corporación Autónoma Regional de los Valles del Magdalena y del Sinú. Bases para un estudio del Desarrollo Integral de la Hoya Hidrográfica del Río Sinú. Programa de Investigación presentado a la consideración del Banco Interamericano de Desarrollo, Bogotá, 1961.

Corte Constitucional, Sentencia T-194 de 1999.
López Gómez,Edmundo y Germán Bula Hoyos. Urrá La más importante obra para el desarrollo de la Costa Atlántica. Bogotá: A.B. Comunicaciones, 1985.

Pernía, Kimy. «El proyecto Urrá según lo hemos visto los embera». En Memorias Foro $\dot{\mathrm{i} P a r a}$ dónde va Urrá? Incidencias y perspectivas de la ejecución del proyecto hidroeléctrico de Urrá, editado por Gloria Amparo Rodríguez, 23. Bogotá: Instituto de Estudios Ambientales idEA, Universidad Nacional de Colombia, 2000.

Sánchez Puche, Paul. Entrevistado por el autor. Bogotá, 5 de marzo de 2009.

\section{Fuentes secundarias}

«Debate contra Urrá». El Tiempo [Bogotá], 2 de octubre, 2002.

«Miles de peces atrapados en Urrá». El Tiempo [Bogotá], 1 de febrero, 1996.

«Otra vez paralizada Urrá». El Tiempo [Bogotá], 19 de octubre, 1992.

Alzate Patiño, Alberto et al. Impactos Sociales del proyecto bidroeléctrico de Urrá. Montería: Fundación del Caribe, 1987.

Cárdenas Támara, Felipe. Antropología y ambiente; enfoques para una comprensión de la relación ecosistema-cultura. Bogotá: Pontificia Universidad Javeriana, 2002.

Consejo Nacional Indígena de Paz (CONIP). «Situación de Derechos Humanos y Derecho Internacional Humanitario Pueblo Embera Katío», 2006. http://www.pcslatin.org/eventos/2006/mision_internacional/cordoba.pdf (consultado el 30 de octubre de 2008).

Ecofondo. Se hace camino al andar: aportes para una bistoria del movimiento ambiental en Colombia. Santa Fe de Bogotá: Ecofondo, 1997.

Mason, Ann C., «Constructing authority alternatives in Colombia: Globalisation transformation of governance». http:www.eldis.org/assets/ Docs/15081.html

Melucci, Alberto. Acción colectiva, vida cotidiana y democracia. México D.F.: El Colegio de México, 1999.

Tanaka, Martín. «Elementos para un análisis de los movimientos sociales». Revista Análisis político, n. 25 (1995): 3-25.

Ulloa, Astrid. La construcción del nativo ecológico: complejidades, paradojas y dilemas de la relación entre los movimientos indigenas y el ambientalismo en 
Colombia. Bogotá: Instituto Colombiano de Antropología e Historia, Colciencias, 2004.

Tobasura Acuña, Isaías. "Ambientalismos y ambientalistas: una expresión del Ambientalismo en Colombia», 2007. http://www.scielo.br/pdf/ asoc/v10n2/a04v10n2.pdf

Wilde, Guillermo. «De la depredación a la conservación. Génesis y evolución del discurso hegemónico sobre la selva misionera y sus habitantes», 2007. http://www.scielo.br/pdf/asoc/v10n1/v10n1a06.pdf Yapa, Kashyapa. «El asesinato ceremonial del río Sinú. Parte II». http://kyapa.tripod.com/urra/ asesinatoceremonial2.htm.
Fecha de recepción: 23 de noviembre de 2014

Fecha de aprobación: 25 de marzo 25 de 2015

Disponible en línea: 30 de agosto de 2015

\section{Cómo citar este artículo}

Leguizamón Castillo, Yeimmy Rocío. «Conflictos ambientales y movimientos sociales: el caso del Movimiento Embera Katío en respuesta a la construcción de la represa Urrá (1994-2008)». Memoria y Sociedad 19, n. 39 (2015): 94-105. http:// dx.doi.org/10.11144/Javeriana.mys19-39.cams 